\title{
ANÁLISE RADIOLÓGICA DA DEGENERAÇÃO DISCAL EXPERIMENTAL EM COELHOS
}

\author{
RADIOLOGICAL ANALYSIS OF EXPERIMENTAL DISC \\ DEGENERATION IN RABBITS
}

Emiliano Vialle', Luiz Roberto Vialle ${ }^{1}$, André de Oliveira Arruda² ${ }^{2}$ Ricardo Nascimento Riet²,

Antônio Bernardo de Queiroz Krieger ${ }^{3}$

\section{RESUMO}

Objetivo: Validar a avaliação radiográfica da degeneração discal experimental em coelhos. Métodos: Os discos intervertebrais lombares de coelhos New Zealand foram puncionados três vezes com uma agulha $18 \mathrm{G}$ com profundidade limitada de $5 \mathrm{~mm}$, através de abordagem lateral. Foram realizadas radiografias seriadas pré e pós-operatórias imediatas, e depois de quatro, oito e 12 semanas do procedimento, com posterior análise da altura discal, formação de osteófito, esclerose da placa vertebral e presença de degeneração discal. A análise estatística dos dados foi validada pelo coeficiente de concordância Kappa, com intervalo de confiança (IC) de 95\%. Resultados: Observou-se diminuição significativa do espaço discal nas radiografias em AP após 12 semanas de pós-operatório, com Kappa $=0,489$ para IC 95\% $(0,25-0,72)$ com $\mathrm{p}<0,001$. Os sinais radiográficos de degeneração discal também apresentaram valor de Kappa = 0,63 para IC 95\% (0,39-0,86) com p < 0,001. Os demais critérios avaliados tiveram resultados positivos, porém, com menor valor de Kappa. Conclusão: $\mathrm{O}$ modelo de degeneração discal em coelhos proposto neste estudo mostrou-se factível, com correlação radiológica positiva entre as imagens pré e pós-operatórias, validando a possibilidade de indução de degeneração discal nesse modelo animal para futuros estudos.

Descritores - Espondilose; Disco intervertebral; Radiologia; Coelhos

\begin{abstract}
Objective: To validate radiographic evaluation of a rabbit model for disc degeneration. Methods: Lumbar intervertebral discs of New Zealand rabbits were stabbed three times with a $18 \mathrm{G}$ needle at a limited depth of $5 \mathrm{~mm}$, through lateral approach. Serial radiographic images were taken on the early pre-and postoperative periods, and after four, eight and 12 weeks of the procedure, with subsequent analysis of disc height, osteophyte formation, endplate sclerosis, and presence of disc degeneration. The statistical analysis of data was validated by the Kappa coefficient, with a confidence interval (CI) of 95\%. Results: A significant reduction of disc space was found on AP X-ray images after 12 postoperative weeks, with Kappa $=0.489$ for CI $95 \%(0.25-0.72)$ with $p<0.001$. X-ray signs of disc degeneration also presented Kappa $=0.63$ for CI 95\% (0.39-0.86) with $p<0.001$. The remaining assessed criteria showed positive results, but with a lower Kappa value. Conclusion: The disc degeneration model using rabbits as proposed in this study was shown to be feasible, with positive X-ray correlation between pre- and postoperative images, validating the potential to induce disc degeneration in this animal model for future studies.
\end{abstract}

Keywords - Spondylosis; Intervertebral disk; Radiology; Rabbits

\footnotetext{
1 - Grupo de Cirurgia de Coluna do Hospital Universitário Cajuru, PUC-PR.

2 - Acadêmico de Medicina, PUC-PR, Bolsista PIBIC 2007-09.

3 - Médico Residente, Serviço de Ortopedia e Traumatologia do Hospital Universitário Cajuru, PUC-PR.
}

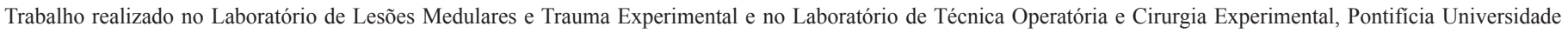
Católica do Paraná.

Correspondência: Dr. Emiliano Vialle, Rua Brigadeiro Franco, 979 - 80430-210 - Curitiba,PR, Brasil. E-mail: emiliano@vialle.com.br. Tel./fax: (41) 3223-7860. 


\section{INTRODUÇÃO}

A degeneração discal compreende a alteração das características estruturais, biológicas e bioquímicas do disco intervertebral (DIV) ${ }^{(1)}$, caracterizando-se por importante perda da rede de proteoglicanos e água do núcleo discal. Isso pode levar à evidência clínica de degeneração - razão do decréscimo da altura discal acarretando aumento de carga nas estruturas próximas à coluna e, finalmente, alterando as suas relações mecânicas ${ }^{(2)}$. Histologicamente, ocorre aumento da proliferação celular com formação de agrupamentos e, paradoxalmente, intensificação da morte de células - tanto pelo processo de apoptose, quanto pela necrose tecidual $^{(3)}$. Alterações moleculares também são encontradas, como a elevação na taxa de produção de citocinas e enzimas destruidoras de matriz (metaloproteinases [MMPs]), interleucina-6, óxido nítrico e prostaglandina $E 2^{(4)}$ além de decréscimo dos seus componentes intracelulares (proteoglicanos), levando à perda gradual de fluido intradiscal ${ }^{(5)}$. Todo esse processo fisiopatológico também é característico do envelhecimento humano normal, havendo relatos de redução gradual da formação de cartilagem na placa de crescimento já a partir dos 16 anos de idade ${ }^{(6)}$, caracterizando o início da discopatia, entretanto, sem gerar quaisquer manifestações clínicas. Com sua evolução natural, devido à degeneração do disco intervertebral, verifica-se que a coluna passa a apresentar instabilidade progressiva da região afetada, conduzindo a uma série de outros eventos nos demais elementos da unidade funcional segmentar ${ }^{(7)}$. Destaca-se ainda que a presença de sintomas relacionados com a DDD (Doença Degenerativa Discal) depende da interação acumulativa de grande grupo de fatores, ambientais e ligados aos hábitos de vida, tais como: micro ou macrotraumatismos, ocupação profissional, tabagismo e aterosclerose, capazes de modificar, em certo grau, a progressão natural da degeneração - geneticamente determinada ${ }^{(8-11)}$.

No polo oposto, quando sintomática, a doença degenerativa discal manifesta-se por dor lombar crônica, sendo de extrema importância epidemiológica e gerando significativos impactos sociais negativos. Diversos estudos evidenciam sua expressiva prevalência, sendo a segunda maior causa de consulta médica nos Estados Unidos $^{(12-16)}$. Em todo o mundo, cerca de 60 a $80 \%$ das pessoas terão dor lombar durante a vida, o que resulta em até 13 milhões de consultas médicas pela queixa citada ao ano, apenas nos Estados Unidos ${ }^{(17)}$. Ainda, segundo dados norte-americanos, 20 bilhões de dólares ao ano são gastos em custos diretos para tratamento da dor lombar crônica, os quais, somados às despesas indiretas, geram um montante que ultrapassa os 100 bilhões de dólares ${ }^{(18)}$.

A fim de amenizar esse quadro alarmante, diversos modelos biológicos de tratamento têm sido propostos, visando futuras aplicações de novas tecnologias terapêuticas e/ou preventivas eficazes; contudo, persistem muitas dúvidas e falhas na abordagem da DDD, fazendo-se necessário o desenvolvimento científico nessa área. Nesse contexto, ganha importância a utilização de modelos animais, os quais, embora não reflitam exatamente as características humanas, apresentam muitas alterações bioquímicas e patológicas idênticas às ocorridas nos humanos ${ }^{(19)}$. Em contrapartida, modelos in vitro impedem a análise do processo de degeneração como um evento complexo, envolvendo diversas estruturas que atuam de forma inter-relacionada e que exercem papéis fundamentais no resultado final, sendo úteis apenas para identificação de processos de curta duração ${ }^{(20)}$.

Há a possibilidade da aplicação de diferentes modelos animais; escolher qual utilizar depende do objetivo a ser atingido. Cada um deles apresenta vantagens e falhas próprias, cabendo ao pesquisador avaliá-las e considerá-las $^{(21)}$.

O objetivo deste estudo consiste em, através da combinação entre as melhores metodologias disponíveis animal utilizado, maneira de indução da degeneração, profundidade da lesão, período e método de acompanhamento evolutivo e tamanho da amostra - validar o método de avaliação radiográfica da degeneração discal experimental em coelhos, baseando-se na confiabilidade interobservador da análise, até então não realizada em estudos anteriores.

\section{MÉTODOS}

\section{Indução da degeneração discal}

$\mathrm{O}$ projeto de pesquisa deste estudo foi avaliado e aprovado pelo Comitê de Ética no Uso de Animais da Pontifícia Universidade Católica do Paraná sob o $n^{\circ}$ 252, parecer $180 / 07$, sendo executado de acordo com as normas da Declaração de Helsinque da Associação Médica Mundial.

Para este estudo, foram selecionados 13 coelhos da raça New Zealand, machos, brancos, pesando entre 3,5 e $4,5 \mathrm{~kg}$, com cerca de um ano de idade. 
Cada animal foi submetido à anestesia pré-operatória com administração intramuscular de cloridrato de cetamina a $5 \%(20-25 \mathrm{mg} / \mathrm{kg})$ - passando para via endovenosa, através de um acesso em veia auricular, caso houvesse necessidade de manter a anestesia por mais de 40 minutos - e xilazina $(0,15 \mathrm{mg} / \mathrm{kg})$ intramuscular. Após a anestesia, foi obtida uma radiografia pré-operatória nas incidências ventridorsal e lateral ${ }^{(22-24)}$, para determinar os valores-base para a altura do DIV.

Após indução anestésica, os coelhos foram posicionados em decúbito lateral direito e submetidos a uma abordagem lateral retroperitoneal esquerda (cerca de $10 \mathrm{~cm}$ ), expondo a superfície lateral de cinco DIVs lombares consecutivos (L2-L3 a L6-L7). Como controle, foram deixados o primeiro e o segundo DIVs (L1-L2 e L2-L3) intactos. Após palpação, sob visão direta do espaço intervertebral para determinar o nível dos discos, as áreas a serem puncionadas (1-2mm de diâmetro) foram cuidadosamente expostas (Figuras 1 e 2).

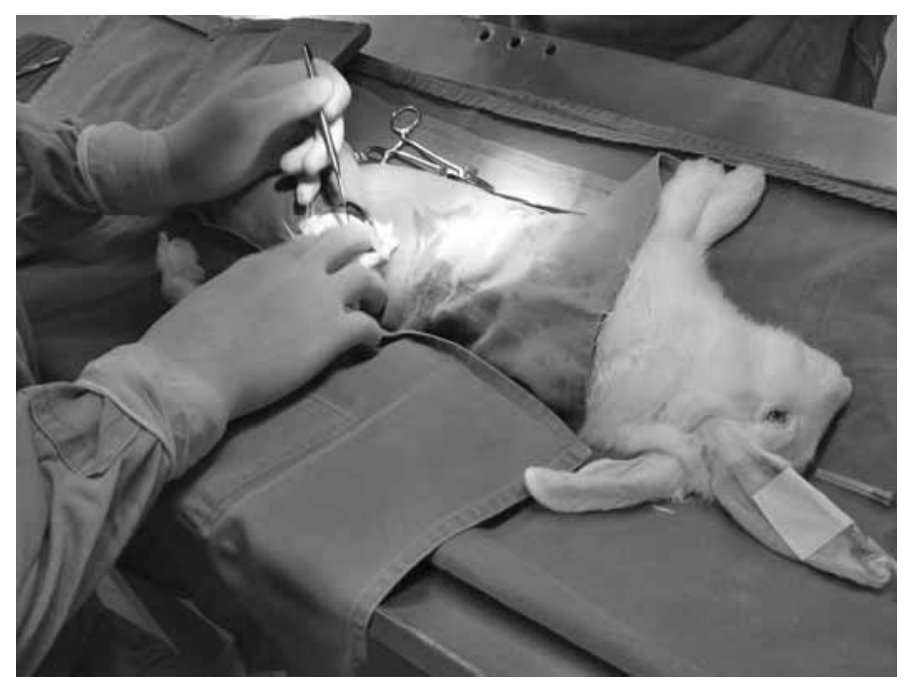

Figura 1 - Início da intervenção cirúrgica

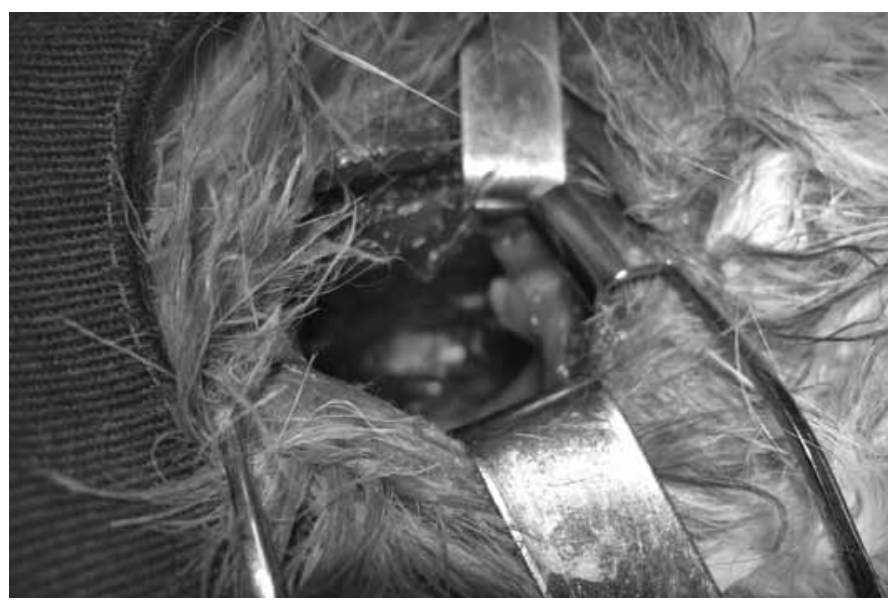

Figura 2 - Exposição dos discos intervertebrais
Os três DIVs caudais foram puncionados três vezes por uma agulha tamanho 18G (Figura 3), com profundidade de exatamente $5 \mathrm{~mm}$, controlada através da moldagem em baioneta (Figura 4). A agulha era inserida na altura central do disco através do anel fibroso dentro do núcleo pulposo, permanecendo ali por cinco segundos. O ferimento decorrente do procedimento cirúrgico era intensamente irrigado em toda sua extensão com solução salina estéril e fechado com sutura. Após o término da sutura, os coelhos eram submetidos a uma nova radiografia da coluna lombar.

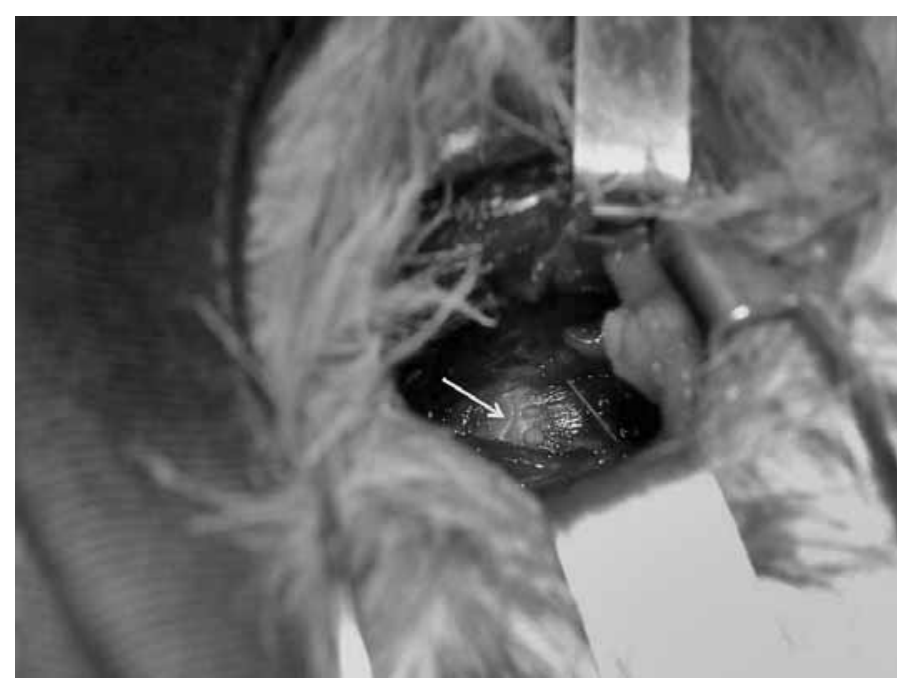

Figura 3 - Punções do DIV (seta)

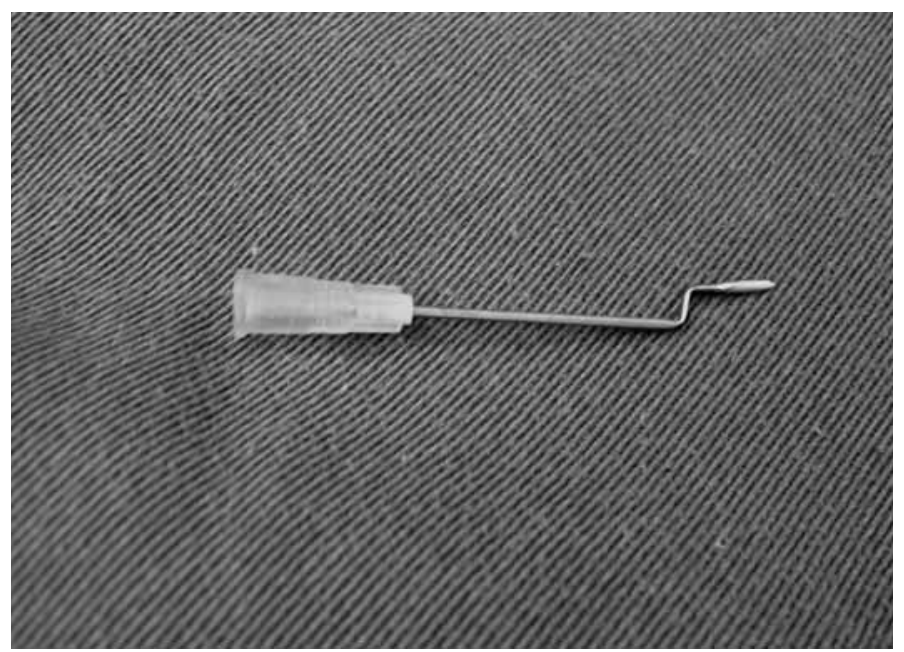

Figura 4 - Agulha $18 \mathrm{G}$ com moldagem em baioneta

\section{Avaliação radiológica}

Para avaliar a altura de cada disco, foram realizadas radiografias de incidência ventridorsal (AP) e lateral (perfil) da coluna lombar logo após a cirurgia, e quatro, oito e 12 semanas depois da intervenção (Figura 5). 
Foi tomado cuidado para manter um nível consistente de anestesia durante a radiografia de cada animal, a fim obter-se um grau similar de relaxamento muscular - o que poderia afetar a altura do disco no exame de imagem. Consequentemente, a radiografia pré-operatória e também a pós-operatória (ambas em alto nível de relaxamento muscular) eram sempre usadas como base de medida. Para diminuir o erro por rotação axial da coluna e por divergência do raio, as radiografias foram repetidas pelo menos duas vezes em cada animal, em posição de decúbito lateral, com o raio centrado a $4 \mathrm{~cm}$ da crista ilíaca do coelho.
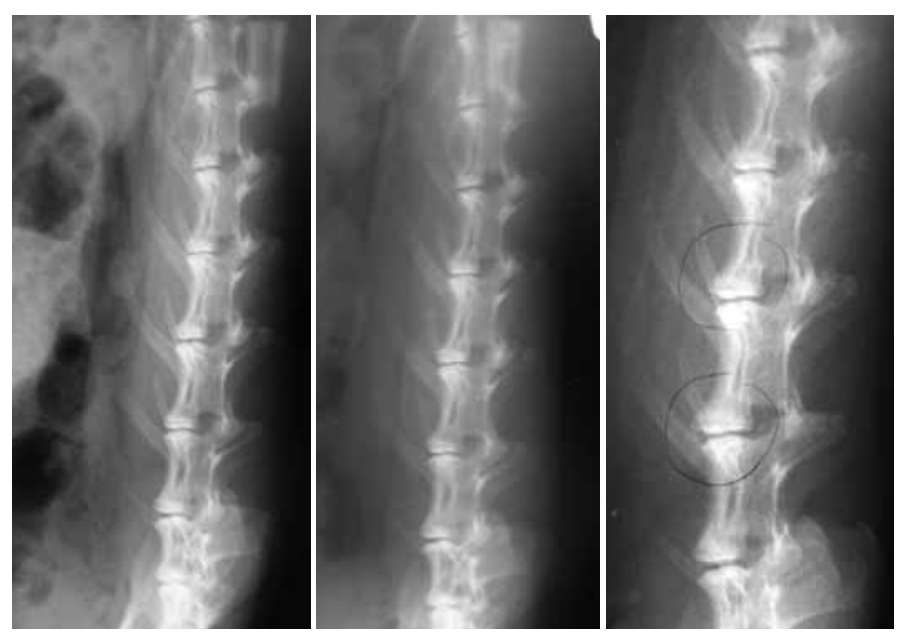

Figura 5 - Radiografia em perfil no pós-operatório imediato (POI) sem alterações; após quatro semanas (4 sem) com evidência de redução do espaço discal; e com oito semanas (8 sem) mostrando formação de osteófitos e esclerose da placa vertebral

Após 12 semanas da cirurgia, os coelhos foram eutanasiados com injeção de dose excessiva de pentobarbital $(90 \mathrm{mg} / \mathrm{kg})$, tendo suas colunas espinhais coletadas para realização de análise histológica e determinação do grau de degeneração.

Para a análise radiológica das mudanças na altura do disco, quatro pesquisadores envolvidos no estudo avaliaram as seguintes variáveis: redução do espaço discal na radiografia em $\mathrm{AP}^{(25,26)}$; redução do espaço discal na radiografia em perfil; formação de osteófito anterior; esclerose da placa vertebral e degeneração discal. A altura dos discos em experimento foi comparada com as de controle e com as radiografias pré e pós-operatórias, sendo então expressa como uma relação. As medidas foram realizadas individualmente e registradas de forma que os avaliadores não tivessem acesso às demais análises.

\section{Análise estatística}

Após a análise individual das radiografias, foi realizada a validação estatística dos resultados para avaliação e graduação de modelo de degeneração discal em coelhos através do coeficiente Kappa ajustado pela prevalência através da abordagem baseada no teste do qui-quadrado para adequação do ajuste. O Kappa é uma medida de concordância interobservador e mede o grau de concordância além do que seria esperado tão-somente pelo acaso. Essa medida de concordância tem valores que variam de 0 a 1; 0 representa não haver concordância além do puro acaso e 1 representa a concordância perfeita ${ }^{(27)}$. A concordância medida pelo Kappa seguirá a orientação de interpretação publicada por Landis e $\mathrm{Koch}^{(28)}$ : Kappa $<0$ - nula; de 0 a 0,19 - discreta; de 0,20 a 0,39 - fraca; de 0,40 a 0,59 - moderada; de 0,60 a 0,79 - substancia;1 e 0,80 a 1,00 - concordância quase perfeita.

\section{RESULTADOS}

Dos 13 coelhos selecionados para a pesquisa, 12 completaram todas as etapas do estudo; um foi a óbito durante o seguimento pós-operatório, não sendo considerados seus resultados.

Após o término do experimento e eutanásia dos animais, quatro pesquisadores do estudo analisaram individualmente as variáveis: redução do espaço discal na radiografia em AP e perfil, formação de osteófito anterior, eslerose da placa vertebral e presença de degeneração discal, através de respostas afirmativas ou negativas ("sim" e "não") para cada categoria avaliada.

A análise estatística dos dados foi validada pelo coeficiente de concordância Kappa, com intervalo de confiança de 95\% (IC 95\%).

A redução do espaço discal na radiografia em AP apresentou valor de Kappa = 0,489 para IC 95\% (0,25$0,72)$ com $p<0,001$. A redução do espaço discal na radiografia em perfil apresentou valor de Kappa $=0,261$ para IC 95\% $(0,03-0,49)$ com $p<0,027$. A formação de osteófitos anterior apresentou valor de Kappa $=0,385$ para IC 95\% $(0,15-0,61)$ com $p<0,001$. A esclerose da placa vertebral apresentou valor de Kappa $=0,329$ para IC 95\% $(0,09-0,56)$ com $p<0,005$. A degeneração discal apresentou valor de Kappa $=0,63$ para IC 95\% $(0,39-0,86)$ com $\mathrm{p}<0,001$.

Utilizando-se a interpretação de Landis e $\operatorname{Koch}^{(28)}$ para os valores de Kappa, temos que a avaliação radiográfica de degeneração discal pelos observadores do 
estudo apresentou concordância substancial, ou seja, tem correlação confiável, com valor estatístico relevante. A redução do espaço discal nas radiografias em AP apresentou concordância moderada, também se mostrando um bom parâmetro de avaliação e validação do resultado. A redução do espaço discal nas radiografias em perfil, assim como a formação de osteófito anterior e a esclerose da placa vertebral, apresentou concordância fraca; embora sejam resultados positivos apropriados, apresentam menor intensidade de concordância interobservadores na validação do modelo de degeneração discal dos coelhos (Tabela 1).

Tabela 1 - Concordância radiológica para modelo de degeneração discal em coelhos

\begin{tabular}{c|c|c}
\hline Variáveis & Kappa (IC 95\%) & Concordância \\
\hline Redução espaço discal AP & $0,489(0,26-0,72)$ & MODERADA \\
\hline Redução espaço discal P & $0,261(0,03-0,49)$ & FRACA \\
\hline Formação osteófito anterior & $0,385(0,15-0,61)$ & FRACA \\
\hline Esclerose placa vertebral & $0,329(0,09-0,56)$ & FRACA \\
\hline Degeneração discal & $0,63(0,39-0,86)$ & SUBSTANCIAL \\
\hline Fonte: Laboratório de Lesões Medulares e Trauma Experimental
\end{tabular}

\section{DISCUSSÃO}

Mesmo após inúmeros trabalhos ${ }^{(22-25)}$ utilizando modelos animais, não existe consenso entre os autores quanto ao modelo animal ideal para o estudo da DDD, bem como das formas de análise necessárias para comprovação da eficácia do modelo, o que permitiria o início da extrapolação dos resultados para os seres humanos. Rousseau et al ${ }^{(25)}$ utilizaram DIVs lombares e caudais de ratos, provocando a lesão por incisões feitas com lâmina $\mathrm{n}^{\mathrm{o}} 11$ de bisturi e analisando quanto à histologia, produção de citocinas, capacidade funcional e propriedades biomecânicas. Kim et al ${ }^{(22)}$ compararam diversos modos de indução de degeneração em coelhos, utilizando injeções intradiscais de Camptothecin (agente apoptótico), aspiração do núcleo pulposo e punção do ânulo fibroso com agulhas $n^{\circ} 18$ e 21, em diferentes níveis lombares, analisando através de ressonância magnética (altura discal) e quanto ao conteúdo líquido final do núcleo. Masuda et $a l^{(24)}$ formaram pequenos grupos experimentais, comparando a degeneração gerada a partir de punções com agulhas $\mathrm{n}^{\circ} 16,18$ e 21 , além da punção com lâmina $\mathrm{n}^{\circ} 11$, avaliando os resultados por meio de radiografias, ressonância magnética e características histológicas. Finalmente, Kroeber et $a l^{(23)}$ aplicaram um dispositivo intersomático externo gerador de carga na coluna lombar de coelhos, verificando os DIVs quanto à rigidez, altura, morfologia e viabilidade celular. Ainda, outro importante ponto em relação aos modelos animais de DDD fundamenta-se na profundidade da lesão gerada no DIV, o que alteraria significativamente os resultados, uma vez que se correlaciona diretamente com a geração de dor, de maneira semelhante à patofisiologia humana. Aoki et $a^{(29)}$ compararam os efeitos de diferentes profundidades de punção, analisando-os imunoistologicamente e por ressonância magnética.

Dessa forma, verifica-se que, mesmo com a existência de modelos animais de degeneração discal, não há consenso entre os estudos, havendo grandes variações metodológicas e de resultados.

Trabalhos experimentais baseados em modelos animais precisam considerar diversos fatores para que seus resultados sejam confiáveis. Inicialmente, a escolha do animal para composição do modelo é crucial, devendo-se, nesse caso, considerar pontos como: disponibilidade, custo de aquisição, facilidade de manuseio, apresentação de DIV de fácil acesso cirúrgico e de tamanho adequado para o procedimento proposto, além da presença de características metabólicas próprias que resultem em início rápido da degeneração discal produzida e que permita análises posteriores seguras $^{(22)}$. Dentro de nossa realidade, encaixaram-se nessas condições dois modelos animais: camundongo e coelho. Confrontando-os, observou-se que coelhos apresentam maiores vantagens por ter discos de dimensões maiores, acesso cirúrgico facilitado e maior facilidade quanto à avaliação das lesões; ainda, mesmo que camundongos tenham maior quantidade de discos - característica bastante importante nesse tipo de estudo - a biomecânica dos discos caudais impede seu uso pela extrema diferença em comparação com a do homem ${ }^{(22-24)}$. O modelo animal adotado para esta pesquisa apresentou vantagens quando comparado com a utilização de animais de maior ou menor porte, tais como ovelhas ou $\operatorname{ratos}^{(25)}$. Em contraste com o estudo em ratos, o comportamento biomecânico da coluna lombar do coelho é mais semelhante ao do humano, em razão da presença de articulações facetárias e musculatura paravertebral ${ }^{(23)}$. Além disso, as placas de crescimento dos corpos vertebrais de coelhos maduros da raça New Zealand estão fechadas, ao contrário dos $\operatorname{ratos}^{(23)}$, havendo também maior dificuldade 
técnica de realizar radiografias confiáveis nesse animal $^{(24)}$. Quando comparado com espécies animais de maior porte, o coelho também apresenta vantagens, tais como sua fácil obtenção, baixo custo de aquisição e de manutenção ${ }^{(22)}$.

Quanto ao método de indução de degeneração discal, a partir da comparação dos estudos, verificou-se a produção de modelos de degeneração lenta e de moderada intensidade através da punção com agulha $18 \mathrm{G}^{(22,24)}$. Seguindo-se a condição preestabelecida, somada à profundidade limitada de $5 \mathrm{~mm}$, descrita como ideal por Aoki et $a l^{(29)}$, verificou-se, nesse estudo, a geração de alterações evidentes nas radiografias de controle, compatíveis com as modificações observadas na degeneração discal intervertebral ocorrida em humanos ${ }^{(3,30-33)}$.

Todos os aspectos radiográficos avaliados neste estudo apresentaram correlação estatística positiva para a validação do modelo de degeneração discal em coelhos. A redução do espaço discal na radiografia em AP foi a alteração mais evidente nas imagens após 12 semanas da indução da degeneração discal por agulha - resultado semelhante ao de outros trabalhos da literatura ${ }^{(24,33)}$.

A análise radiográfica em 12 semanas pós-operatórias mostrou alterações evidentes na estrutura do disco intervertebral, tais como a diminuição do espaço discal, formação de osteófitos, presença de esclerose da placa vertebral e evidência de degeneração discal, concordante entre os observadores, com correlação estatística validada. Kim et $a l^{(22)}$, Masuda et $a l^{(24)}$ e Sobajima et $a l^{(33)}$ obtiveram resultados semelhantes da indução de degeneração discal em coelhos através de punção por agulha, mostrando-se um método eficaz, de fácil realização e menor taxa de complicações quando comparado com outras técnicas descritas ${ }^{(23,34,35)}$.

A aplicação de um método seriado de acompanhamento evolutivo destaca-se na literatura. Uma vez que a DDD apresenta características próprias de acordo com o estágio em que se encontra, há grande necessidade de avaliações periódicas. Verifica-se, em outros estudos, a aplicação da ressonância magnética nesse processo ${ }^{(22,33)}$. Entretanto, a partir da análise radiográfica, permitiu-se a diferenciação estatisticamente confiável entre a presença/ausência de degeneração discal, utilizando-se uma tecnologia de maior acessibilidade, menos dispendiosa e que requer menor infraestrutura. De semelhante modo, o período uniforme de avaliação seriada permitiu a verificação final de resultados significativos quanto à presença de degeneração.
Esse tipo de estudo apresenta característica especial devido ao tamanho da amostra, estando baseada no número absoluto de discos e não na quantidade de animais utilizados, sendo cada disco uma variável independente quanto ao critério absoluto de presença ou ausência de degeneração. Muitos resultados apresentados nos modelos animais para DDD baseiam-se em pequenas amostras, algumas vezes subdivididas em grupos de acordo com diferentes métodos de indução de degeneração discal aplicados em cada segmento. Kim et al $^{(22)}$ utilizaram, ao total, nove DIVs para cada metodologia experimental empregada; Kroeber et al ${ }^{(23)}$ desenvolveram seu modelo com 33 animais; entretanto, cinco compuseram o grupo controle e os 28 restantes foram divididos em grupos, sofrendo eutanásia seriada, restando apenas sete exemplares com o período evolutivo completo de dois meses, diminuindo a expressividade da análise evolutiva; Rousseau et $a l^{(25)}$, mesmo tendo empregado um número expressivo de animais experimentais (ratos), também tiveram sua amostra dividida por eutanásia seriada, sendo o tempo máximo de 28 dias. Diferentemente, esse estudo realizou a análise de 60 DIVs, todos submetidos a um procedimento uniforme de indução de degeneração discal e tendo sido acompanhados seriadamente sob condições idênticas, gerando um número expressivo em relação ao apresentado na literatura.

Sendo assim, os resultados apresentados possibilitam a realização de estudos futuros visando a estratégias terapêuticas para a DDD, com destaque à sua potencial aplicação direta no estudo de terapias celulares.

\section{CONCLUSÃO}

O modelo de degeneração discal em coelhos proposto neste estudo mostrou-se factível, com correlação radiológica positiva entre as imagens pré e pós-operatórias, validando a possibilidade de indução de degeneração discal neste modelo animal para futuros estudos e comprovando o papel da radiografia na identificação da degeneração discal.

\section{AGRADECIMENTOS}

- À equipe do Departamento de Técnica Operatória, pelo apoio na realização dos experimentos;

- À equipe do Departamento de Medicina Veterinária, pelo apoio na realização dos estudos radiográficos;

- Ao Sr. Misael Gomes Barbosa, pela atenção e cuidado com os animais utilizados neste estudo. 


\section{REFERÊNCIAS}

1. Nerlich A, Schleicher E, Boos N. Immunohistologic markers for age-related changes of human lumbar intervertebral discs. Spine. 1997;22(24):2781-95.

2. Larson JW 3rd, Levicoff EA, Gilbertson LG, Kang JD. Biologic modification of animal models of intervertebral disc degeneration. J Bone Joint Surg Am. 2006;88(Suppl 2):83-7.

3. Johnson WE, Eisenstein SM, Roberts S. Cell cluster formation in degenerate lumbar intervertebral discs is associated with increased disc cell proliferation. Connect Tissue Res. 2001;42(3):197-207.

4. Kang JD, Georgescu HI, McIntyre-Larkin L, Stefanovic-Racic M, Donaldson WF 3rd, Evans $\mathrm{CH}$. Herniated lumbar intervertebral discs spontaneously produce matrix metalloproteinases, nitric oxide, interleukin-6, and prostaglandin E2. Spine. 1996;21(3):271-7.

5. Brisby H. Pathology and possible mechanisms of nervous system response to disc degeneration. J Bone Joint Surg Am. 2006;88(Suppl 2):68-71.

6. Bernik S, Cailliet R. Vertebral endplates changes with aging of and human vertebrae. Spine. 1983;8:151-61.

7. Puertas EB, Yamashita H, Oliveira VM, Souza PS. Classificação por ressonância magnética da degeneração do disco intervertebral. Acta Ortop Bras. 2009;17(1): 46-9

8. Nunes F, Teresa B, Conforti-Froes NDT, Negrelli WF, Souza DRS. Fatores genéticos e ambientais envolvidos na degeneração do disco intervertebral Acta Ortop Bras. 2007;15(1):9-13.

9. Bhatia N, Wang J. Current information regarding the biochemical and genetic events that occur during disc degeneration. Curr Opin Orthop. 2003;14(3):153-8.

10. Videman T, Leppävuori J, Kaprio J, Battié MC, Gibbons LE, Peltonen L, et al. Intragenic polymorphisms of the vitamin $\mathrm{D}$ receptor gene associated with intervertebral disc degeneration. Spine. 1998;23(23):2477-85.

11. Battié $M$, Videman $P$, Eric P. Lumbar disc degeneration: epidemiology and genetic influences. Spine. 2004;29(23):2679-90.

12. Andersson GB. Epidemiological features of chronic low-back pain. Lancet. 1999;354(9178):581-5.

13. Andersson GB. The epidemiology of spinal disorders. In: Frymoyer JW. The adult spine: principles and practice. 2nd ed. Philadelphia: Lippincott-Raven; 1997. p.93-141

14. Praemer A, Furnes S, Rice DP. Musculoskeletal conditions in the United States. Rosemont, IL: AAOS; 1992. p.1-99.

15. Taylor VM, Deyo RA, Cherkin DC, Kreuter W. Low-back pain hospitalization: recent United States trends and regional variations. Spine. 1994;19(11):1207-13.

16. Hart LG, Deyo RA, Cherkin DC. Physician office visits for low back pain. Spine. 1995;20(1):11-9.

17. Spivak JM, Bendo JA. Lumbar degenerative disorders In: Orthopaedic Knowledge Update 7. Rosemont, IL: AAOS; 2002. p.627-44.

18. Katz JN. Lumbar disc disorders and low-back pain: socioeconomic factors and consequences. J Bone Joint Surg Am. 2006;88(Suppl 2):21-4.

19. Sobajima S, Shimer AL, Chadderdon RC, Kompel JF, Kim JS, Gilbertson LG, et al. Quantitative analysis of gene expression in a rabbit model of intervertebral disc degeneration by real-time polymerase chain reaction. Spine $\mathrm{J}$ 2005;5(1):14-23.

20. Goel VK, Panjabi MM, Patwardhan AG, Dooris AP, Serhan H. Test protocols for evaluation of spinal implants. J Bone Joint Surg Am. 2006;88(Suppl 2):103-9.

21. Lotz JC. Animal models of intervertebral disc degenation - Lessons learned. Spine. 2004;29(23):2742-50.

22. Kim KS, Yoon ST, Li J, Park JS, Hutton WC. Disc degeneration in the rabbit: a biochemical and radiological comparison between four disc injury models. Spine. 2005;30(1):33-7.

23. Kroeber MW, Unglaub F, Wang H, Schmid C, Thomsen M, Nerlich A, et al. New in vivo animal model to create intervertebral disc degeneration and to investigate the effects of therapeutic strategies do stimulate disc degeneration. Spine. 2002;27(23):2684-90.

24. Masuda K, Aota Y, Muehleman C, Imai Y, Okuma M, Thonar EJ, et al. A novel rabbit model of mild, reproducible disc degeneration by an anulus needle puncture: correlation between the degree of disc injury and radiological and histological appearances of disc degeneration. Spine. 2005;30(1):5-14.

25. Rousseau MAA, Ulrich JA, Bass EC, Rodriguez AG, Liu JJ, Lotz JC. Stab incision for inducing intervertebral disc degeneration in the rat. Spine. 2007;32(1):17-24.

26. Lipson SJ, Muir H. 1980 Volvo award in basic science. Proteoglycans in experimental intervertebral disc degeneration. Spine. 1981;6(3):194-210.

27. Cohen J. A coefficient of agreement for nominal scales. Educ Psychol Meas. 1960;20(1):37-46.

28. Landis JR, Koch GG. The measurement of observer agreement for categorical data. Biometrics 1977;33(1):159-74.

29. Aoki H, Akeda K, An H, Muehleman C, Takahashi K, Moriya H, et al. Nerve fiber ingrowth into scar tissue formed followed nucleus pulposus extrusion in the rabbit anular-puncture disc degeneration model: effects of depth of puncture. Spine. 2006;31(21):774-80.

30. Pritzker KP. Animal models for osteoarthritis: processes, problems and prospects. Ann Rheum Dis. 1994;53(6):406-20.

31. An HS, Masuda K. Relevance of in vitro and in vivo models for intervertebral disc degeneration. J Bone Joint Surg Am. 2006;88(Suppl 2):88-94.

32. Battié MC, Videman T. Lumbar disc degeneration: epidemiology and genetics. J Bone Joint Surg Am. 2006;88(Suppl 2):3-9.

33. Sobajima S, Kompel JF, Kim JS, Wallach CJ, Robertson DD, Vogt MT, et al. A slowly progressive and reproducible animal model of intervertebral disc degeneration characterized by MRI, X-ray, and histology. Spine. 2004;30(1):15-24.

34. Zhou H, Hou S, Shang W, Wu W, Cheng Y, Mei F, et al. A new in vivo animal model to create intervertebral disc degeneration characterized by MRI, radiography, CT/discogram, biochemistry, and histology. Spine. 2007;32(8):864-72.

35. Fazzalari NL, Costi JJ, Hearn TC, Fraser RD, Vernon-Roberts B, Hutchinson $\mathrm{J}$, et al. Mechanical and pathologic consequences of induced concentric anular tears in an ovine model. Spine. 2001;26(23):2575-81. 